\title{
GESTÃO DE RESÍDUOS DA CONSTRUÇÃO CIVIL
}

\section{ARTIGO ORIGINAL}

NOGUEIRA, Cristiany da Silva ${ }^{1}$

NOGUEIRA, Cristiany da Silva. Gestão de Resíduos da Construção Civil. Revista Científica Multidisciplinar Núcleo do Conhecimento. Ano 05, Ed. 11, Vol. 10, pp. 6784. Novembro de 2020. ISSN: 2448-0959, Link de acesso:https://www.nucleodoconhecimento.com.br/arquitetura/residuos-daconstrucao

\section{RESUMO}

O artigo tem como propósito pesquisar a área da construção civil no que diz respeito à geração quantitativa e a atual gestão dos resíduos de construção e demolição oriundos do canteiro de obras da construção civil localizados na cidade de Manaus no Amazonas. Destacando as atividades de construções e demolições, causadoras de graves impactos socioambientais, materiais esses que demandam de resoluções rápidas para uma gestão adequada enfocando em uma disposição de reutilização dos mesmos e assim causando impactos na cadeia produtiva da construção civil. A metodologia utilizada foi uma abordagem e entendimento da aplicação das técnicas de acordo coma resolucao 307/2002 do Conama e outras ações Municipais em Manaus e com visitas as empresas para verificar o funcionamento e aplicabilidade dessas diretrizes. Amostragem dos resultados demonstra que na área da construção civil as empresas pesquisadas não se encaixam conforme à Resolução ํㅜ 307/2002 do Conama as mesmas não possuem profissionais com formação específica no que diz respeito a coletas de entulho na área de gestão de resíduos e que depositam os resíduos no Aterro Sanitário de Manaus. De acordo com os resultados obtidos nesse estudo, cerca de $50 \%$ dos resíduos pertencem a classe A. Neste contexto, foi

\footnotetext{
${ }^{1}$ MBA Construção Sustentável e Edificação Eficiente. Arquiteta e Urbanista.
} 
proposto ações futuras, a fim de reutilizar os resíduos advindos da construção civil como soluções adequadas ao municipio de Manaus, de modo ambiental e social.

Palavras-chave: Construção civil, resíduos da construção civil, gerenciamento.

\section{INTRODUÇÃO}

Popularmente conhecido no Brasil como entulho ou sobras, indo para um termo ou uma linguagem tecnica a nomeclatura a ser utiliza e de Resíduos de Construção e Demolição (RCD) que consistem em todos ou qualqer material processados nas atividades de constroção civil, esses materiais são procedentes dos reparos, demolições das obras de construção civil, os residuos de escavação de terrenos são considerados de Resíduos de Construção e Demolição (RCD).

Hendriks (2000) e Pinto (1999) observaram os volumes dos resíduos urbanos são gerados através dos processos construtivos. Esse grande acúmulo de resíduos se da devido à baixa cobertura dos serviços de coleta e as precárias condições de destino final dos mesmos, não obstante pode ser observar a necessidade urgente de uma implantação de políticas, que objetivam a diminuição do da produção de resíduos sólidos (MELO; FROTA, 2013).

Processos deficientes na construção civil são por muitas vezes danosos ao meio ambiente e a produção, péssima qualidade de material empregado, perdas no transporte e armazenamento, outro problema e a manipulação inadequada por parte da mão de obra. Para tentar reduzir o desperdício e necessário uma melhoria na gestão das obras públicas, com objetivo de fortalecer o trabalho conjunto entre as empresas e trabalhadores da construção civil. (MELO; FROTA, 2013).

Não obstante, por muitas vezes o entulho e retitado de forma clandestina sendo disposto em terrenos baldios e nas ruas de bairros perifericos. Todavia não ha um comprometimento mensuravel por parte das prefeituras no que tange a remoção ou tratamento dos entulhos. Há muito trabalho para retirar o entulho das margens de rios, assim como o de limpar as galerias e realizar a dragagem dos leitos dos córregos, onde na maioria das vezes o material terminar por se depositado. 
Os RCDs apresentam uma grande variedade e depedem da situação e atividade das obras onde são executadas. Os resíduos em sua maioria são gerados, normalmente, em grandes quantidades, este grande volume representa uma parcela expressiva de resíduos descartados na sociedade (CRUZ, 2018). Segundo o relatorio do Instituto de Pesquisa Economica Aplicada (IPEA) os residuos solidos da construção civil possuem entrave em sua destinação: separação dos materiais, destinação incorreta por tipo de material, ausência de planejamento na determinação dos planos de reaproveitamento de material, dentre outros. Assim sendo, se observa a necessidade de realizar um planejamento adequado para otimizar o uso adequado dos Resíduos Sólidos da Construção Civil (RCC), sendo crucial formalutar políticas públicas que permitem o desenvolvimento de ações que atendam a essa demanda (IPEA, 2012).

O objetivo central do trabalho é demonstrar as ações em RCD desenvolvidas em obras em Manaus-AM, verificando a realidade no qual se encontram as empresas que trabalham com esse tipo material. Ademais, analisar se as obras observadas estão de acordo com a Resolução 307 do Conselho Nacional do Meio Ambiente.

\section{METODOLOGIA APLICADA}

A pesquisa inicial do trabalho se da através de um levantamento bibliográfico, a fim de buscar entender e identificar através da literatura cientifica as principais aplicações sobre os resíduos sólidos na construção civil a partir da perspectiva da destinação final. A etapa seguinte da pesquisa foi realizada através de um trabalho de campo, onde foram visitados alguns canteiros de obras de Manaus-AM, também foram visitados locais de descarte das empresas do setor de coleta e transporte de materiais de entulho. Com objetivo de obter resultados no processo de: Quantificação do RCD em Manaus; origem e segregação; armazenamento; destino final.

\section{ANÁLISE E CARACTERIZAÇÃO}

Conforme a resolução de n. $307^{\circ}$ da CONOMA a responsabilização dos resíduos da construção civil é do poder público, tendo então a iniciativa privada o apoio para a criação de um planejamento adequado de destinação dos resíduos sólidos. 
(CONAMA, 2002). Dessa forma, é fundamental observar que a responsabilização do resíduo é do gerador, porém, o poder público tem o papel de fiscalizar o processo e garantir que a destinação seja realizada de forma correta e dentro das normativas legais vigentes (CREA/SP, 2005).

A Resolução fala da obrigatoriedade de um Plano Integrado de Gerenciamento dos Resíduos da Construção Civil para os Municípios. (CONAMA, 2002). O plano tem que adotar soluções diferenciadas para os pequenos volumes, fica a cargo do poder público municipal, e para os grandes volumes, fica a cargo da iniciativa privada. Devido isso, deverá ser elaborado o Termo de Referência de Gerenciamento de RCD contendo os procedimentos para pequenos e grandes geradores e transportadores que ainda deverão ser definidas, licenciadas e disponibilizadas áreas de manejo para os RCD, dentro do prazo estipulado pela meta que estipula até 2017. A resolução coloca também sobra à identificação e o cadastramento dos grandes geradores e o credenciamento dos transportadores.

Oliveira e Mendes (2008) citando John e Agopyan, (2003) explicam de ações que direcionam para diminuição da criação de resíduos na construção civil entre elas estão: investimento em tecnologia, desenvolvimento de projeto e planejamento de destinação com base na demanda. Assim,garante a melhoria do material usado na construção, reduzindo a manutenção causada pela correção de defeitos. A reciclagem de entulho mais usada tem sido com base no processo de pavimentação e resuo do solo com base em técnica de mistura de materiais (ZORDAN, 1997).

No entanto tem que ser tomada bastante cautela e observar vários pontos para utilização do RCD na engenharia. De acordo com Angulo e John (2004) os resíduos não advêm apenas de materiais metálicos, adequados eles possuem outros materiais como: gesso, madeira, materiais metálicos, ferro, plástico, dentre outros. Conforme a NBR 10.004 (ABNT, 2004), o resíduo da construção e demolição civil esta classificada como resíduo inerte, porém também existem os materiais que podem tornar o material danoso, como o amianto. Na Tabela 1 são apresentados dados da composição do entulho em algumas cidades brasileiras. 
Tabela 01 - Composição do entulho de algumas cidades brasileiras

\begin{tabular}{|c|c|c|c|c|}
\hline \multirow[t]{2}{*}{ Material } & \multicolumn{4}{|c|}{ Origem (\%) } \\
\hline & $\begin{array}{l}\text { São } \\
\text { Carlos }\end{array}$ & São Paulo & $\begin{array}{l}\text { Ribeirão } \\
\text { Preto }\end{array}$ & Salvador \\
\hline $\begin{array}{ll}\text { Concreto } & \text { e } \\
\text { argamassa }\end{array}$ & 69 & 33 & 59 & 53 \\
\hline Solo e areia & - & 32 & - & 22 \\
\hline Cerâmica & 29 & 30 & 23 & 14 \\
\hline Rochas & 1 & - & 18 & 5 \\
\hline Outros & 1 & 5 & - & 6 \\
\hline
\end{tabular}

Fonte: (CARNEIRO et al.,2001 apud MELO; FROTA, 2013)

Mendes e Oliveira explicam:

A um dispositivo importante empregado nessa problemática ambiental é a implantação de programas de gestão desse resíduo. Um mecanismo importante criado para tal finalidade foi a Resolução 307 (CONAMA, 2002), a qual define, para a construção civil, quatro classes de resíduos, que deverão ter tratamentos distintos:

Classe A - resíduos reutilizáveis ou recicláveis, como agregados, tijolos, blocos, telhas, placas de revestimento, argamassas, concretos, tubos, meio-fio, solos de terraplanagem, etc;

Classe B - resíduos recicláveis para outras destinações, tais como plásticos, papel/papelão, metais, madeiras, etc;

Classe C - resíduos ainda sem tecnologias ou aplicações economicamente viáveis para a sua reciclagem/recuperação, tais como os oriundos do gesso (tratamento pelo gerador);

Classe D - perigosos, como tintas, solventes, óleos e outros, ou aqueles contaminados (tratamento pelo fabricante). (OLIVEIRA; MENDES, 2008). 
Ademais a classificação dos resíduos, que enseja um manejo de forma mais adequada, auxiliando o emprego dos resíduos como uma alternativa de material reciclado nas mais diversas áreas da construção civil. E estabelecido também que o gerenciamento fica sobre responsabilidade dos municípios (AZEVEDO; KIPERSTOK; MORAES, 2006).

Conforme o Plano Municipal de Gestão Integrada de Resíduos Solidos em Manaus (PMGIRS), (MANAUS, 2015). A Lei Municipal №001/2010 art. 133 em complementação junto à Lei 12.305/2010 art. 20 que determina os geradores sujeitos à elaboração do plano de gerenciamento de resíduos, encontram-se citados os geradores de serviços públicos, resíduos sólidos urbanos, domiciliares e de limpeza urbana, e os abaixo especificados:

- Estabelecimentos comerciais e de prestação de serviços;

- Os estabelecimentos que geram resíduos perigosos;

- Os estabelecimentos de construção civil, que não sejam equiparados aos resíduos domiciliares pelo poder público municipal, e os dispostos nos termos da Lei Municipal №001/2010 e normas instituídas pelos órgãos do SISNAMA.

- Os estabelecimentos de serviços de transportes, os portos, aeroportos, terminais alfandegários, rodoviários e ferroviários;

- Estabelecimentos responsáveis por atividades agrossilvopastoris se determinado pelo órgão competente do Sistema Nacional do Meio Ambiente (SISNAMA) e se couber Sistema Nacional de Vigilância Sanitária (SNVS).

- Resíduos industriais: os gerados nos processos produtivos e instalações industriais;

- Resíduos de Serviços de Saúde - RSS: os gerados nos serviços de saúde, conforme definido em regulamento e em normas estabelecidas pelos órgãos do SISNAMA e do SNVS;

Há um Plano de Resíduos sólidos para a cidade de Manaus, o PDRS-Manaus objetiva orientar o sistema de limpeza pública de Manaus a fim de promover seu desenvolvimento criando diretrizes e metas para o fortalecimento institucional, 
administrativo tudo isso visando o tratamento adequado e uma correta disposição final dos resíduos sólidos, onde estes devem classificados e agrupados segundo o local no qual foram originados e, ainda, de acordo com sua periculosidade. (IBAM, 2010).

$\mathrm{Na}$ figura 1 pode ser visto os conceitos da indentificação, classificação e caracterização dos resíduis solidos. Isto possibilta o agrupamento correto dos resíduos gerados no município.

Figura 01 - Layout básico de um centro de coleta 


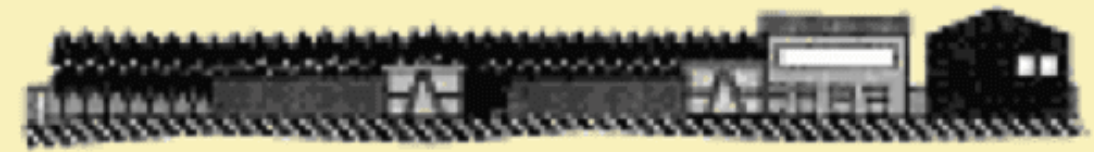

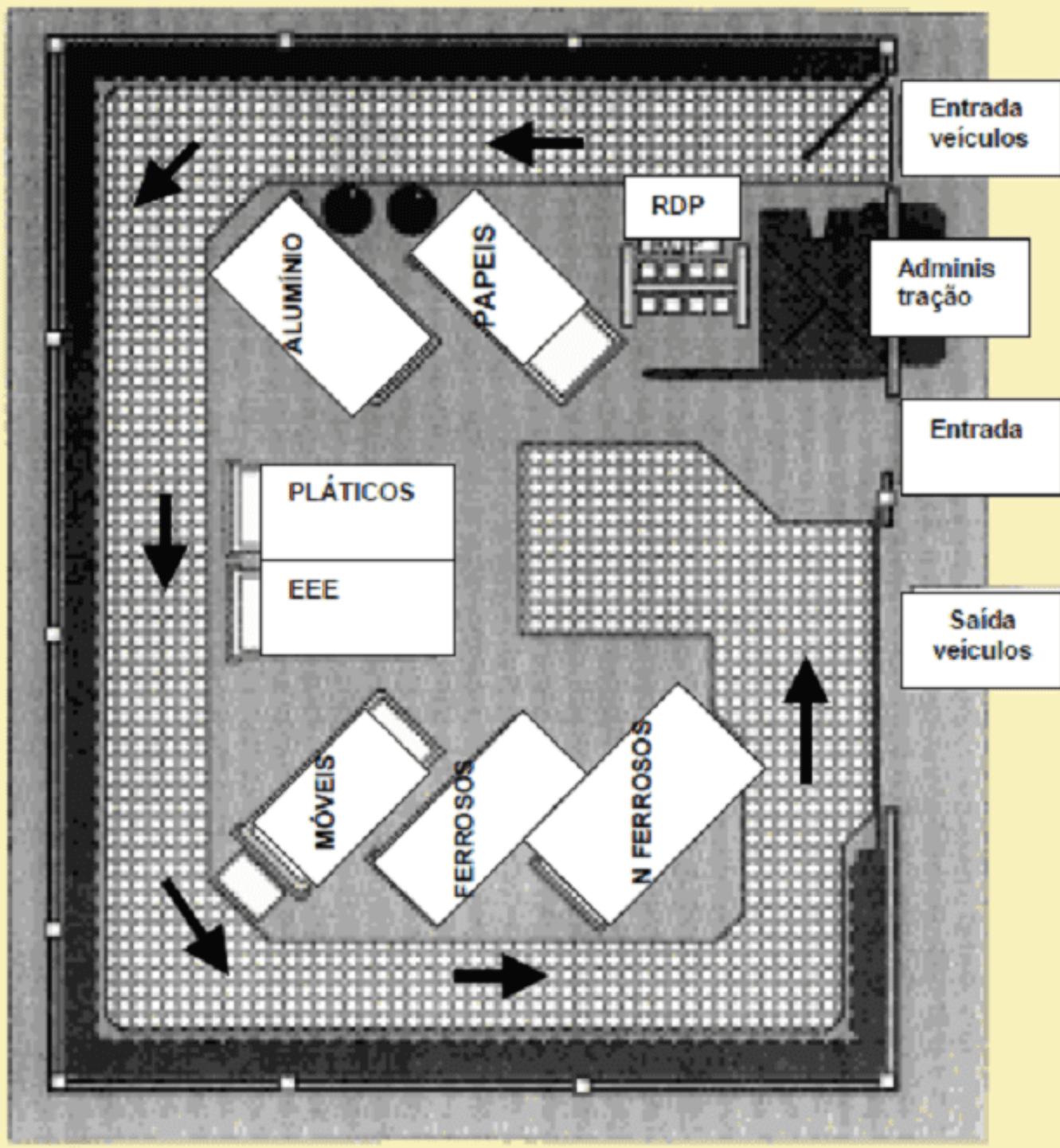

Fonte: Plano Diretor de Resíduos sólidos de Manaus

As centrais de coleta vão auxiliar o usuário na destinação dos residuosdomiciliares não perigosos e perigosos - de coleta seletiva e residuos especiais. O funcionamento deverá ser garantido pela formalização de parcerias pelos responsaveis da coleta dos diversos materiais e o Município. (IBAM, 2010). 
Abaixo segue as etapas do Plano de Resíduos Sólidos e de Coleta Seletiva da Região Metropolitana de Manaus:

ETAPA I: COORDENAÇÃO DA ELABORAÇÃO DO PLANO DE RESÍDUOS SÓLIDOS E COLETA SELETIVA

ETAPA II: DIAGNÓSTICO DA SITUAÇÃO DA GESTÃO DE RESÍDUOS SÓLIDOS E DE COLETA SELETIVA

ETAPA III: PROGNÓSTICOS E CENÁRIOS PARA GESTÃO DE RESÍDUOS SÓLIDOS E DE COLETA SELETIVA

ETAPA IV: MEDIDAS PARA O PLANO QUANTO AOS DISTINTOS TIPOS DE RESÍDUOS E DE COLETA SELETIVA

ETAPA V: MONITORAMENTO E GERENCIAMENTO DO PLANO DE RESÍDUOS SÓLIDOS E COLETA SELETIVA

ETAPA VI: PUBLICAÇÃO E OFICIALIZAÇÃO DO PLANO DE RESÍDUOS SÓLIDOS E COLETA SELETIVA - RMM

DETALHAMENTO DE CADA ETAPA:

ETAPA I - COORDENAÇÃO DA ELABORAÇÃO DO PLANO DE RESÍDUOS SÓLIDOS E COLETA SELETIVA

A etapa de coordenação da elaboração do PRSCS-RMM consiste na fase de planejamento, onde se efetuou as ações:

Elaboração do Plano de Operacionalização das Etapas/Tarefas do PRSCS-RMM;

Elaboração do Plano de Pesquisa e Desenvolvimento;

Elaboração do Plano de Comunicação Social;

Elaboração do Plano de Mobilização Social. 
Nessa etapa os esforços foram concentrados na definição de uma equipe para execução de contratos, contratação consultores especialistas na area assim como a formulação de prognóatico

\section{ETAPA II - DIAGNÓSTICO DA SITUAÇÃO DA GESTÃO DE RESÍDUOS SÓLIDOS E DE COLETA SELETIVA}

Conforme a Lei 12.305 em seu art. 17, inciso I, o diagnóstico de resíduos sólidos do estado do Amazonas será elaborado para a identificação dos principais fluxos de resíduos do Estado e seus impactos socioeconômicos e ambientais.

\section{ETAPA III: PROGNÓSTICOS E CENÁRIOS PARA GESTÃO DE RESÍDUOS SÓLIDOS E DE COLETA SELETIVA}

Como determina a Lei 12.305 em seu art. 17, inciso I, e o Decreto 7.404 em seu art. 48, a proposição de cenários será elaborado visando a descrição de um futuro possível, imaginável e desejável na gestão estadual de resíduos sólidos para o horizonte de 20 anos. Os cenários vão servir de referência para o planejamento no horizonte temporal adotado, refletindo as expectativas favoráveis e desfavoráveis para aspectos como crescimento populacional; intensidade de geração de resíduos; mudança no perfil de resíduos; incorporação de novos procedimentos; novas capacidades gerenciais, etc. (BRASIL, 2012).

\section{ETAPA IV - MEDIDAS PARA O PLANO QUANTO AOS DISTINTOS TIPOS DE RESÍDUOS E DE COLETA SELETIVA}

Como determina a Lei 12.305 em seu art. 17, inciso I, e o Decreto 7.404 em seu art. 48, o Plano de Resíduos da Região Metropolitana deve contemplar. A disposição final ambientalmente adequada dos rejeitos, o consumo sustentável e a integração dos catadores de materiais reutilizáveis e recicláveis nas ações que envolvam a responsabilidade compartilhada pelo ciclo de vida dos produtos.

Os Programas de Coleta Seletiva a ser elaborado distintamente para cada município da RMM deverão abranger o que determina os artigos 18 e 19 da Lei 12.305/2010 e 
o artigo 49 do Decreto no 7.404/2010 e deveram contemplar os seguintes conteúdos estabelecidos pelo Edital de Chamada Pública SRHU/MMA no 001/2011, e outros:

I - divisão do município em setores para Coleta Seletiva;

II - distribuição, pré-dimensionamento e lay-out das instalações para a Coleta Seletiva, tais como: pontos de entrega voluntária (PEVs), locais de entrega voluntária (LEVs), galpões de triagem dos resíduos secos, áreas de transbordo e triagem (ATTs), áreas de reciclagem e beneficiamento dos resíduos da construção civil, compostagem de resíduos orgânicos, entre outras;

III - dimensionamento e qualificação das equipes necessárias para a correta operacionalização da Coleta Seletiva;

IV - definição de requisitos mínimos de segurança e saúde do trabalhador no manejo dos Resíduos Sólidos da Coleta Seletiva;

V - levantamento dos equipamentos e formas de transporte para implantação da Coleta Seletiva, inclusive a combinação adequada entre os mesmos;

VI - definição de rotas e frequência para a coleta e transporte dos materiais recicláveis;

VII - estruturação do processo de logística reversa, observando o mercado local, regional e nacional.

Ainda serão propostos programas prioritários para os resíduos que têm presença mais significativa nas cidades, dado levantado na fase de diagnóstico e pelos estudos de composição gravimétrica, por se tratarem de ações que mais empregaram recursos humanos, físicos e financeiros.

ETAPA V - MONITORAMENTO E GERENCIAMENTO DO PLANO DE RESÍDUOS SÓLIDOS E COLETA SELETIVA 
O acompanhamento, controle e fiscalização do Plano envolvem questões tais como, a verificação do cumprimento dos objetivos definidos no PRSCS-RMM; a observância dos dispositivos legais aplicáveis à gestão dos resíduos sólidos; a identificação dos pontos fortes e fracos do plano elaborado e das oportunidades e entraves a sua implementação; a efetividade da implementação do Plano por meio da aferição das metas estabelecidas e a proposição de adequações e demais ajustes necessários. Nesta etapa serão construídos indicadores que devem permitir uma análise gráfica entre a meta prevista e a realizada nos períodos determinados pelo PRSCS-RMM.

\section{ETAPA VI - PUBLICAÇÃO E OFICIALIZAÇÃO DO PLANO DE RESÍDUOS SÓLIDOS E COLETA SELETIVA - RMM}

A versão do Plano de Resíduos Sólidos para Consulta Púbica consiste na reunião de todos os produtos anteriormente elaborados, que deverá ser submetido à aprovação popular por meio de Audiência Pública.

Fonte: Residuos Sólidos Amazonas

\section{OS IMPACTOS AMBIENTAIS CAUSADOS PELA CONSTRUÇÃO CIVIL}

A terminologia impacto ambiental corresponde às interferências associadas àimplantação de projetos, cujas atividades sócioeconômicas ou de uso e ocupação dosolo podem sofrer alterações, havendo a necessidade de caracterizar aquelas alterações que são ou não significativas. (KRAFTA, 1997).

$\mathrm{Na}$ cidade de Manaus, os problemas ambientais, principalmente daquelesrelacionados à construção civil, não são diferentes do resto do Brasil. De acordo com os órgãos ambientais da cidade de Manaus, o setor da construção civil é um dosprincipais interventores e modificadores do meio ambiente, em quase todas as suas atividades. (MACIEL, 2003).

Ainda a autora explica:

A construção civil é uma indústria diferenciada pelo seu caráter artesanal, geralmente executada a céu aberto, sujeita às variações 
climáticas e a baixa qualificação de sua mão-de-obra. Os produtos da construção civil, tais comoloteamentos, multifamiliares verticais e residências, são marcados por característicaspeculiares, porém não seguem um padrão único ou um modelo, em particular. (MACIEL, 2003).

Maciel (2003) em sua pesquisa fala que as atividades da construção civil em Manaus, assim como em outras cidades,possuem rotinas e processos semelhantes, diferenciando-se pelo porte e tipo deserviço. Em sua maioria, os impactos são gerados pela modificação doambiente utilizado e da área envoltória. Com o propósito de minimizar os impactos causados pela construção civil, os órgãos fiscalizadores competentes licenciam as atividades consideradas impactantes, comojá foi citado anteriormente. Durante o processo de licenciamento, visitas técnicas sãorealizadas para avaliar o empreendimento. Um roteiro, não padronizado, é seguidopelo órgão licenciador, no qual é levada em consideração a alteração causada peloempreendimento.

Os aspectos observados, em geral, estão relacionados ao porte do empreendimento e ao tipo de impacto ambiental provocado, tais como poluição doscursos d'água, ocupação da faixa de preservação permanente, degradação do solo, desmatamento excessivo e destinação dos resíduos sólidos produzidos pelo empreendimento. (MACIEL, 2003).

A caracterização dos estudos de caso apresentados levou em consideração aspectos analisados ao longo do processo de licenciamento, sendo estes o desmatamento, o uso da área de preservação permanente, a presença de cursod'água, o tratamento de efluentes aderidos e a execução das exigências legais. Bem como, observou-se os fatores indicativos de sustentabilidade. Estes fatores referem-se a utilização do solo, da infra-estrutura sanitária, dos recursos ambientais conservados, do controle da poluição e da destinação dos resíduos. (MACIEL, 2003).

A finalidade da resolução Conselho Nacional do Meio Ambiente - CONAMA № 307, publicada em 05 de julho de 2002, responsabiliza tanto o poder público como as empresas privadas no que diz respeito a destinação dos residuos solidos da 
constração civil. Torna também obrigatorio a criação de planos integrados de gerenciamento nos municipios.

\section{PRINCIPAIS PONTOS DA RESOLUÇÃO}

1. Os resíduos sólidos da construção civil são dispostos em locais inadequados, o que leva à degradação ambiental;

2. Representam um significativo percentual dos resíduos sólidos produzidos nas áreas urbanas;

3. São resíduos provenientes de atividades de construção, reforma reparos e demolições de estruturas e estradas, remoção de vegetação e escavação de solos.

\section{LEVANTAMENTO DE PESQUISA}

1-Quantificação RCD Manaus

O aterro sanitário do município de Manaus recebe os mais diversos residuos. As empresas são obrigadas a se cadastrar para poder adentrar com caminhão no aterro, eles são direcionados para balança onde solcitado seu devido regsitro, e sua licença ambiental.

Figura 02 - Gráfico de Destinação de Resíduos no Aterro 


\section{Destinaçao dos Resíduos no Aterro}

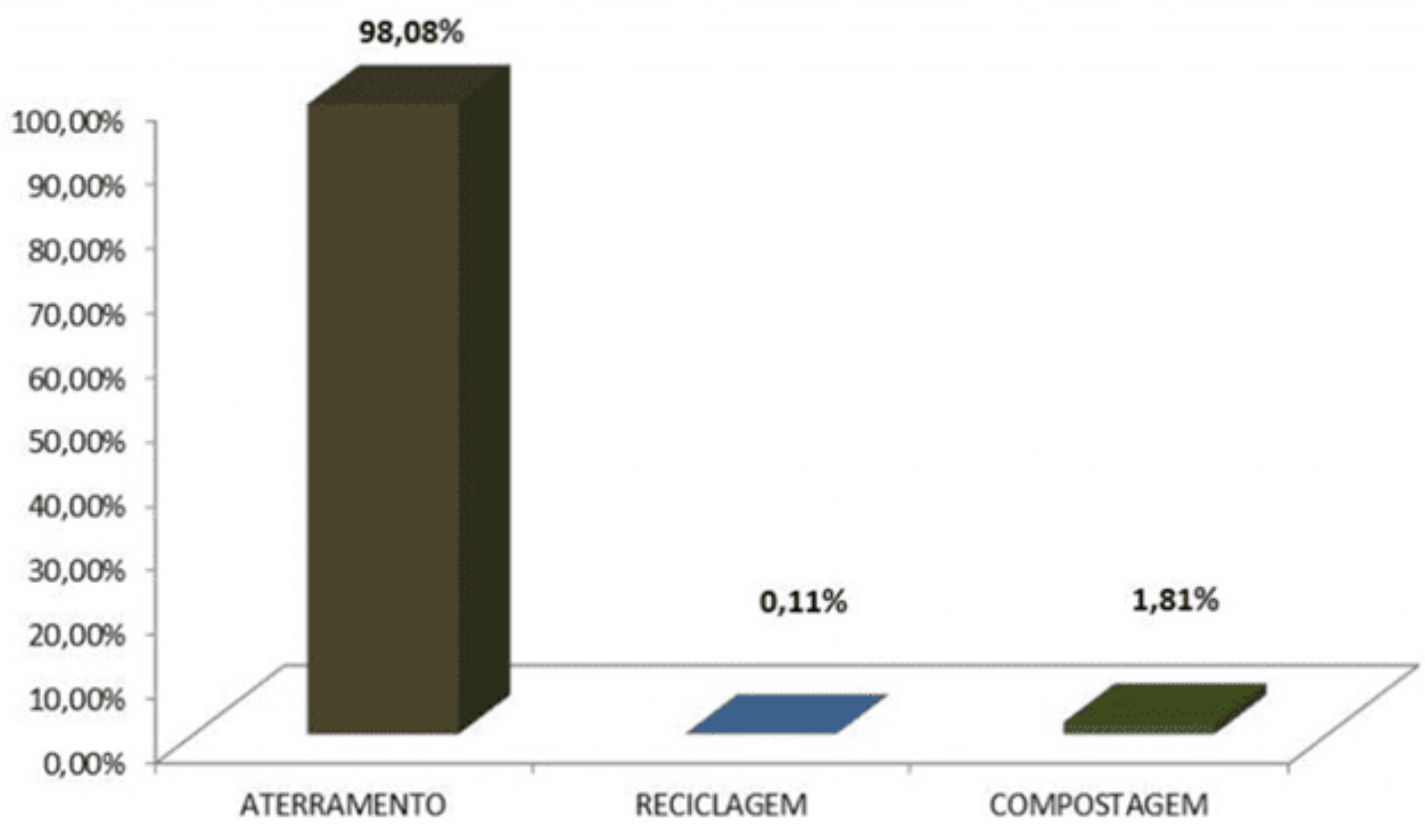

Fonte: Site SEMULSP, 2013.

\section{2-Origem e Segregação}

Foi realizada a pesquisa junto as construtoras credenciadas em Manaus fala sobre 0 Sindicato da Indústria da Construção Civil do Amazonas (SINDUSCON/AM). Identificou-se que o planejamento para a destinação dos resíduos sólidos ainda está em fase de elaboração, seguindo todas as recomendações. Entretanto, ainda não existe um planejamento de gerenciamento fixo e único utilizado pelas empresas.

A segregação de residuos devem seguir as recomendações legais com observância específica para a separação dos materiais. De acordo com Mazur (2015) há a necessidade de manter a limpeza ideal dos espaços de trabalho para evitar, além do acúmulo desnecessário de materiais utilizados, garantir a proteção dos trabalhadores e, assim, evitar qualquer tipo de acidente de trabalho.

\section{3-Armazenamento}

O processo de armazenamento é realizado com base na organização dos materiais coletados e reaproveitados. A destinação é realizada de acordo com a procedência 
do material e o modo de reuso de cada empresa coletora e reciclagem. Alguns são destinados para trabalhos com madeira, setor artístico, tijolos, tapumes, aproveitamento para canteiros de obras, setor artístico, dentre outros. Os materiais que não são aproveitados seguem para o aterro municipal para compor a destinação e o reuso para outros fins.

A Figura 3 apresenta uma caçamba que é utilizada para o depósito de materiais pesados, geralmente os eletrodomésticos e materiais descartados com uma grande proporção de volume. Essa caçamba é importante para coletar os materiais e garantir que não haja descarte na calçada ou na rua, sendo ideal para evitar esse tipo de descarte inadequado. Além disso, ela funciona acoplada ao caminhão por meio de uma base mecânica que funciona para o despejo no veículo. A sua capacidade volumétrica é de $5 \mathrm{~m}^{2}$ e possui um acondicionamento ideal para cargas de alto impacto, sem que haja risco de perfuração ou rompimento da sua estrutura.

Figura 03 - Caçamba estacionária em frente a um canteiro de obras. 


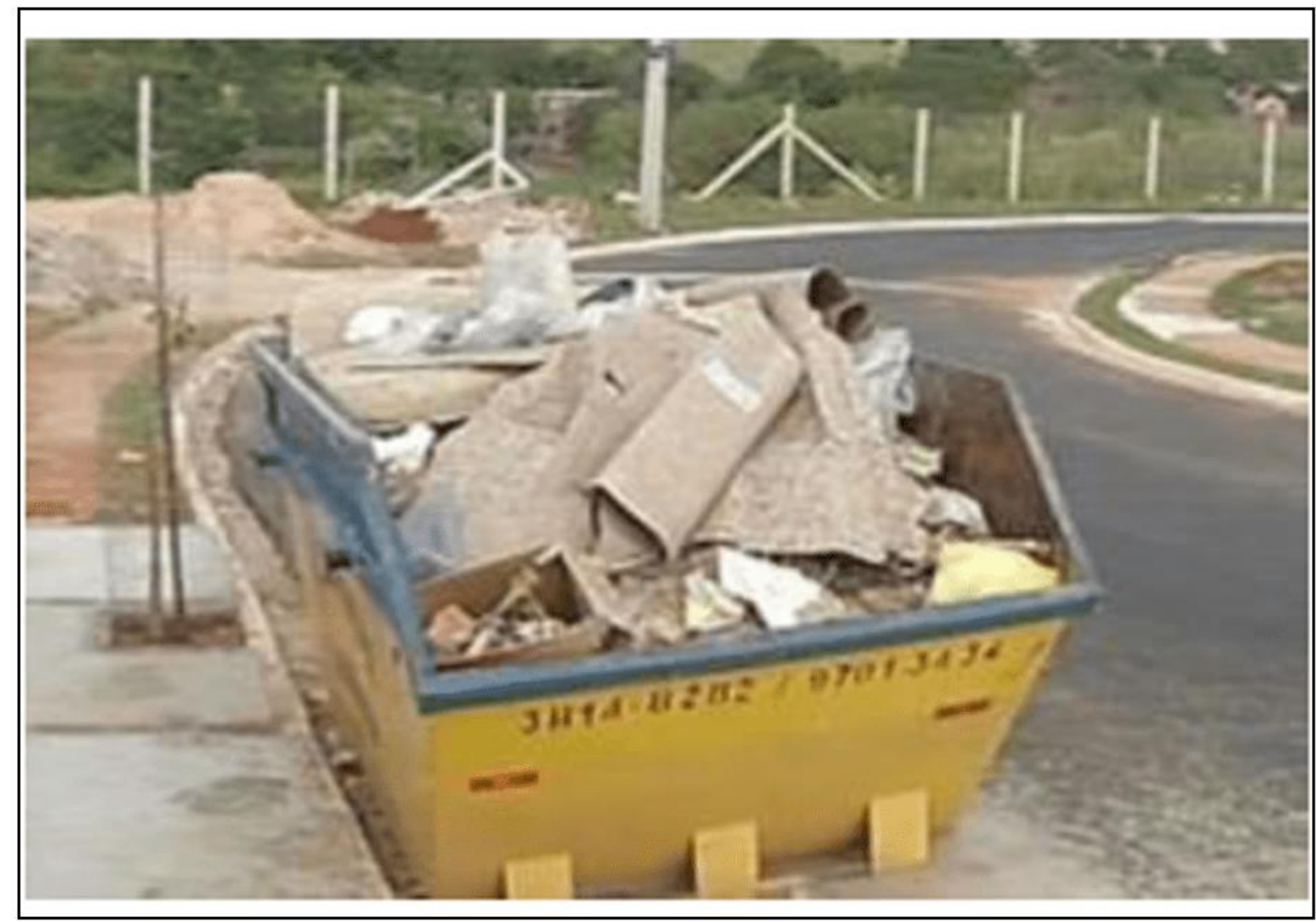

Fonte: Site SEMULSP, 2013.

De acordo com Mota (2014) a figura 04 demonstra as etiquetas adesivas, utilizadas para sinalizar resíduos provenientes da coleta seletiva, onde serão colocados com a indicação do material a ser acondicionado. O azul identifica "papel/papelão", o Vermelho identifica o "plástico"; o Verde identifica o "vidro"; o Amerelo identifica o "metal"; o Preto identifica a "madeira"; o Laranja identifica os "resíduos perigosos"; o Branco identifica "resíduos ambulatoriais e de serviços de saúde"; o Roxo identifica os "resíduos radioativos"; o Marrom identifica os "resíduos orgânicos"; e o Cinza os "resíduos geral não reciclável ou misturado, contaminado ou não passível de reuso".

Figura 04 - Etiquetas adesivas, para indicação dos resíduos. 


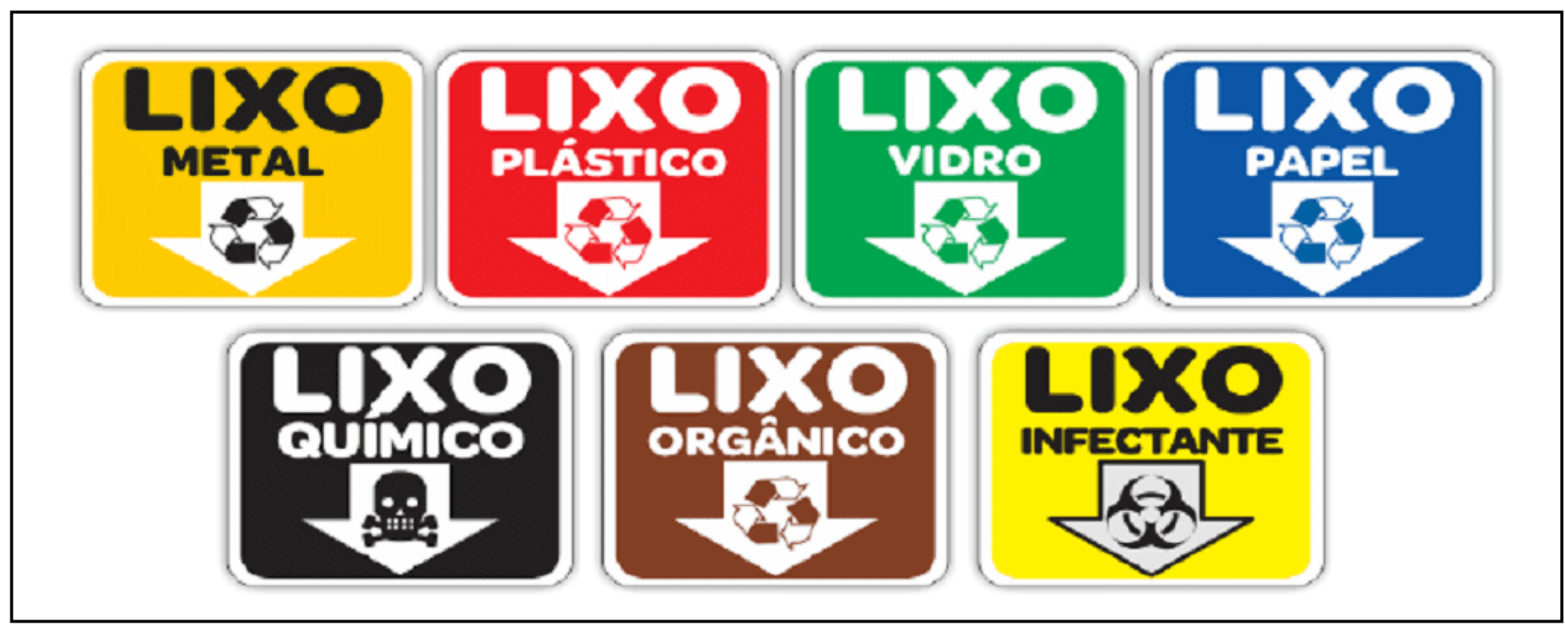

Fonte: Site SEMULSP, 2013.

\section{4-Destino Final}

De acordo com dados observados na Secretaria Municipal de Limpeza Pública SEMULSP, atualmente, há mais de 60 empresas que atuam no trabalho de reciclagem na cidade. Elas atuam no mercado de reciclagem e trabalham em um modelo de cooperativismo e associativismo, sendo então cadastradas e monitoradas pela Prefeitura. Ainda há uma grande implicação no processo de reuso desse material, tendo em vista que muitos ainda destinam o material direito para o aterro municipal, sem passar por qualquer processo de separação para a reciclagem.

Para os volumes de resíduos no mercado da construção civil, Mota (2014) observa que ainda há uma grande dificuldade do poder público em acondicionar esses materiais devido ao problema no depósito e manutenção desses materiais sem que haja um despejo inadequado. Ainda existe uma cultura de descarte do material utilizado na construção civil no meio ambiente e em terrenos baldios, o que pode implicar em crimes ambientais e problemas relacionados a poluição ambiental e contaminação de rios e igarapés.

Observou-se que em Manaus as empresas que desenvolvem o trabalho na área da reciclagem trabalham em sistema de cooperativismo, porém ainda com pouca atuação em áreas ambientais. Algumas empresas desenvolvem o seu trabalho na área de recuperação de pneus e no processo de trituração e processamento na produção de 
cimentos, localizadas na área do Distrito Industrial. Ademais, o mercado do processamento de papel (celulose) também é um mercado atuante em algumas empresas, tendo em vista que essa produção é garantida por meio do reaproveitamento de material para a garantia da matéria-prima.

\section{RESULTADOS E DISCUSSÕES}

A pesquisa observou que as empresas desenvolvem o seu RCD com base em um prognóstico e levantamento do volume de materiais para reuso e reciclagem. Entretanto, não foi observado uma aferição mais apurada, tendo em vista que algumas empresas não desenvolvem um trabalho mais específico para apresesentar um quantitativo mais adequado com os materiais da construção civil.

Foi observado que as empresas da construção civil, com seus Planos de Gerenciamento de Resíduos Sólidos da Construção Civil - PGRSCC, encontram dificuldades para atender aos requsitos legais, tendo em vista o encarecimento da produção devido ao custo com logística e distribuição. Ademais, grande parte do processo de distribuição e armazenamento é realizado por empresas terceirizadas, pois as empresas não dispõem desse serviço específico, e assim então as empresas, em alguns casos, deixam de trabalhar com o reaproveitamento dos materiais devido a esses entraves.

A ausência de um Plano Municipal de Gestão de Resíduos Sólidos em Manaus dificulta o processo de reciclagem dos resíduos sólidos, pois não há usinas especializadas para esse trabalho e as empresas, dentre elas da construção civil, não possuem um amparo legal para fomentar a prática de destinação dos materiais. Esse entrave pode resultar em uma destinação inadequada dos materiais, levando então para uma consequentente degradação ambiental por meio de um descarte inadequado desses materiais.

Observou-se no estudo a necessidade de uma usina de reciclagem para o municipio de Manaus, tendo em vista que, por ser um grande centro urbano e com um desenvolvimento aquecido do mercado da construção civil, há a necessidade de 
desenvolver soluções para viabiliar o processo de reciclagem dos materiais da construção civil, assim como dos resíduos domésticos, a fim de que seja evitado qualquer tipo de degradação ambiental por meio de descarte inadequado.

A contribuição do estudo parte da observação da ausência do plano de destinação do municipio e a indicação da implantação de um modelo ideal de gerenciamento dos resíduos sólidos da construção civil no municipio, haja vista que o comprometimento com o meio ambiente deve ser um assunto precípuo na definição de qualquer política pública que atenda aos principios de sustentabilidade.

\section{CONCLUSÃO}

Manaus é uma cidade que não possui um planejamento de gestão para os resíduos sólidos da construção civil, logo, enfrenta problemas por não possuir um RDC e não seguir as diretrizes preconizadas pela Resolução no 307/2002 do Conama. Diante exposto, essa dificuldade incide em uma falha de controle e gestão de resuso dos materiais para reuso, que incide em um processo inadequado de destinação e pode ocasionar um agravamento dos casos de poluição ambiental

Observou-se no estudo que, com base na pesquisa realizada nas empresas, nenhuma apresentou uma adequação da Resolução n 307/2002 do Conama, mesmo com um planejamento direcionado para o gerenciamento dos resíduos sólidos da construção civil. Entretanto, não houve a identificação de um planejamento em nenhumas das empresas pesquisadas, sendo que em todos os processos de investigação do tratamento dos resíduos sólidos observados no estudo, não há qualquer planejamento de destinação veiculado a um plano do RDC, pois as mesmas alegaram dificultades, dentre elas: terceirização do serviço e aumento do custo devido a logística e ao armazenamento.

Por conseguinte, o estudo aponta como indicação para pesquisas futuras a realização de outras análises sobre o processo de gerenciamento de resíduos sólidos em Manaus-AM nos próximos anos, tendo em vista que a necessidade de otimizar a gestão ambiental dentro do mercado da construção civil é uma demanda urgente da 
cidade. Sugere-se que, além da elaboração do Plano de Gerenciamento de Resíduos Sólidos, o poder público e a iniciativa privada repensem um modelo estrutural e aplicável que atenda a construção civil, a fim de que o reaproveitamento dos materiais em projetos de construção civil estejam atrelados aos princípios da sustentabilidade.

\section{REFERÊNCIAS}

ANGULO, S. C.; JOHN, V. M. Variabilidade dos agregados graúdos de resíduos de construção e demolição reciclados. e-Mat - Revista de Ciência e Tecnologia de Materiais de Construção Civil. v. 1, n.1, p. 22-32, maio 2004. Disponível em: http://www.emat. info/e-MAT-V1-N1/e-MAT-V1-N1-p22-32.pdf . Acesso em: 08 nov. 2019.

ASSOCIAÇÃO BRASILEIRA DE NORMAS TÉCNICAS. NBR 10.004: resíduos sólidos. Rio de Janeiro, 2004.

AZEVEDO, Gardênia Oliveira David de; KIPERSTOK, Asher; MORAES, Luis Roberto Santos. Resíduos da construção civil em Salvador: os caminhos para um gestão sustentável. Eng. Sanit. Ambent. v.11, n.01 - jan/mar 2006, p. 65-72

BRASIL. Decreto n o 7.404, de 23 de dezembro de 2010. Regulamenta a Lei № 12.305, de 2 de Agosto de 2010, que institui a Política Nacional de Resíduos Sólidos, cria o Comitê Interministerial da Política Nacional de Resíduos Sólidos e o Comitê Orientador para a Implantação dos Sistemas de Logística Reversa. Disponível em: http://www.planalto.gov.br/ccivil_03/_ato2007-

2010/2010/Decreto/D7404.htm Acesso em: 05 abr. 2019.

. Lei № 12.305, de 2 de Agosto de 2010. Política Nacional de Resíduos

Sólidos.

Disponível

em:

http://www2.mma.gov.br/port/conama/legiabre.cfm?codlegi=636 Acesso em: 28 abr.2019. 
CONSELHO NACIONAL DO MEIO AMBIENTE (BRASIL). Resolução № $\mathbf{3 0 7}$, de $\mathbf{5}$ de julho de 2002. Ministério das Cidades, Secretaria Nacional de Habitação. Publicada no Diário Oficial da União em 17/07/2002.

CONSELHO REGIONAL DE ENGENHARIA, ARQUITETURA E AGRONOMIA DO ESTADO DE SÃO PAULO. Guia profissional para uma gestão correta dos resíduos da construção. São Paulo: CREA/SP, 2005.

CRUZ, Zozimere do Carmo da Silva. Os resíduos sólidos da construção civil na cidade de Manaus. Revista especialize ON - LINE IPOG. Goiânia, GO, Ano 9, n. 16, v. 1, p. $01-16,2018$. Disponivel em: https://assets.ipog.edu.br/wpcontent/uploads/2019/12/07015611/zozimere-do-carmo-da-silva-171310195.pdf Acesso em: 03 de mar. 2018.

HENDRIKS, $\mathrm{CH}$. F. Durable and sustainable construction materials. The Netherlands: Aeneas Technical Publishers, 2000.

INSTITUTO BRASILEIRO DE ADMINISTRAÇÃO MUNICIPAL - IBAM. Plano Diretor de Resíduos Sólidos de Manaus. 2010. 155 p. Área de Desenvolvimento Urbano e Meio Ambiente.

Disponível

em: http://www.ibam.org.br/media/arquivos/estudos/plano_diretor_residuos_solidos_man aus.pdf. Acesso em: 05 abr. 2019.

IPEA - INSTITUTO DE PESQUISA ECONOMICA APLICADA. Diagnostico dos resíduos sólidos da construção civil: relatório de pesquisa. Brasília, DF: Ipea, 2012.

KRAFTA, R. Avaliação de desempenho urbano. In: ANPUR - Associação Nacional de Pós Graduação e Pesquisa em Planejamento Urbano Regional, 7, 1997. Anais... Recife, 1997.

MACIEL, Jussara Socorro Cury. Alternativas sustentaveis de gestão ambiental na construção civil em Manaus. 2003. 111 f. Disseratção (Mestrado em Ciências do Ambiente e Sustentabilidade na Amazônia) - Programa de Pós - Graduação em 
Ciênias do Ambiente e Sustentabi idade na Ama zô nia PPG/CASA, Amazonas, AM, 2003.

MANAUS (AM). Secretaria Municipal de Limpeza Urbana. Plano municipal de gestão integrada de resíduos sólidos de Manaus. Manaus: SEMULSP, 2015.

MAZUR, Joyce. Residuos solidos da construção civil e a logistica reversa no canteiro de obras vinculados á saúde e segurança do trabalhador. 2015. $51 \mathrm{f}$. Trabalho de conclusão de curso (Especialista no curso de pós - gradução em engenharia de segurança do trabalho) - Universidade Tecnologica Federal do Paraná, Curitiba, PR, 2015.

MELO, João Ricardo de Souza; FROTA, Consuelo Alves da. A situação dos resíduos sólidos oriundos da construção civil vertical na cidade de Manaus. T \& C Amazônia. Manaus, AM, Ano X, n. 23, p. 32 - 39, 2013.

MOTA, Jeane da Rocha. A destinação dos resíduos sólidos da construção civil em manaus: do canteiro de obras ao destino fina. 2014. 72 f. Dissertação (Mestrado Profissional em Processos Construtivos e Saneamento Urbano) - Programa de Mestrado Profissional em Processos Construtivos e Saneamento Urbano da Universidade Federal do Pará. Belém, PA, 2014.

OLIVEIRA, Edieliton Gonzaga de; MENDES, Osmar. gerenciamento de resíduos da construção civil e demolição: estudo de caso da resolução 307 do conama. 2008. Dispnível em: https://mac.arq.br/wp-content/uploads/2016/03/estudo-de-casoconstrutora-consciente.pdf. Acesso em: 24 de jan. 2020.

PINTO, T. P. Metodologia para gestão diferenciada resíduos sólidos da construção urbana. São Paulo, 1999, 189 f. Tese (Doutorado) - Escola Politécnica da Universidade de São Paulo, 1999.

SILVA, Otavio Henrique da et al. Etapas do gerenciamento de resíduos da construção civil. Revista Eletrônica em Gestão, Educação e Tecnologia Ambiental. Santa Maria, v. 19, 2015, p. $39-48$. 
ZORDAN, S.E. A utilização do entulho como agregado, na confecção do concreto. Campinas. 1997. 140p. Dissertação (Mestrado) - Faculdade de Engenharia Civil, UNICAMP. Disponível em

[http://www.reciclagem.pcc.usp.br/entulho_ind_ccivil.htm]. Acesso em: 27 jul. 2019.

Enviado: Agosta, 2020.

Aprovado: Novembro, 2020. 